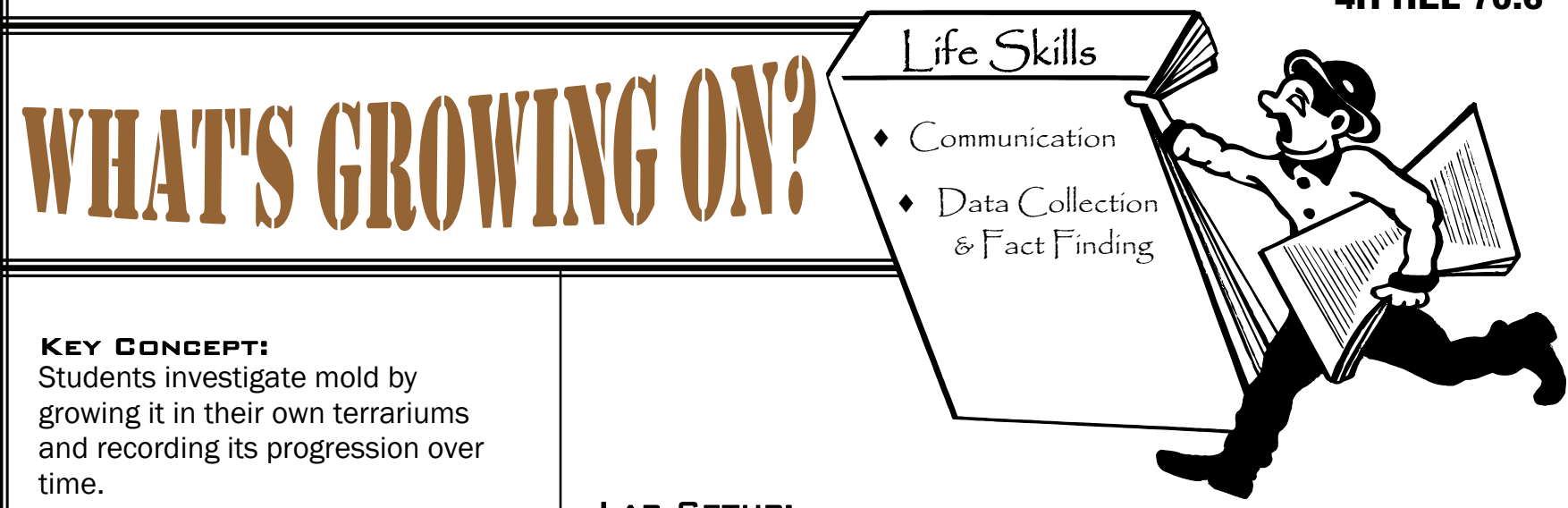

SUBJECT MATTER QUTCOME: Students will be able to identify mold and the conditions which promote mold growth.

TARgeted Age: $5^{\text {th }}$ Grade

TIME NEEDED:

DAY 1 - 30 minutes for intro lesson; 15 minutes to prepare jars

ADDITIONAL DAYS - 5-10 minutes each day to observe, record, and briefly discuss progress

\title{
MAterials NeEded:
}

- Worksheet Set 2.1 (1 per student)

- Masking tape

- Water at room temperature

- Variety of food scraps

- One container with lid per child Container must be disposable, clean, and transparent.

AdVance Preparation: Review Project Overview and Background Basics

FLORIDA SUNSHINE STATE STANDARDS:

HE.A.1.2.5

HE.B.1.2.2

HE.B.3.2.2

HE.C.2.2.1

SC.G.1.2.4

SC.G.1.2.6

SC.G.1.2.7
SC.G.2.2.3

SC.H.1.2.1

SC.H.1.2.2

SC.H.1.2.3

SC.H.1.2.4

SC.H.2.2.1

\section{LAB SETUP:}

- Don't use items with meat or fish in them; they will smell awful!

- Include some foods that are pre-packaged. Packaged foods contain a lot of preservatives and will not grow mold easily.

This creates a nice comparison topic for discussion.

- Try to get a good variety of food in different jars so students can see the difference between foods

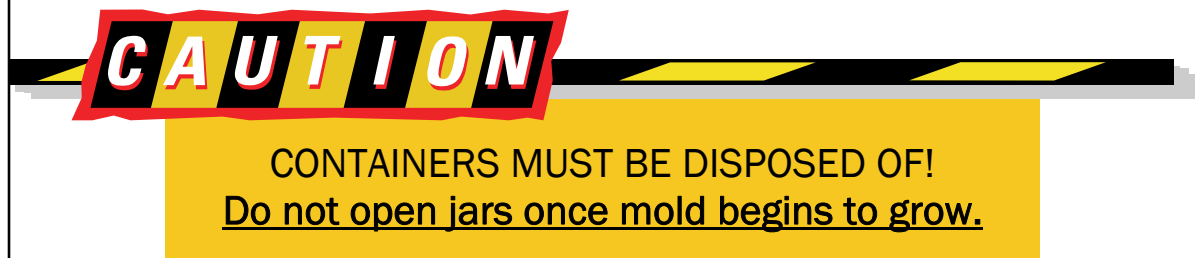

\section{LET'g BELIN}

Today's hazard is part of a special group of living organisms called fungi (fun-jī or fun-gi ). They are not plants and they are not animals. Unlike plants, fungi have no flowers or leaves. The fungi uses nutrients from other foods or plants to grow as they decompose the original food or plant. Some fungi are really

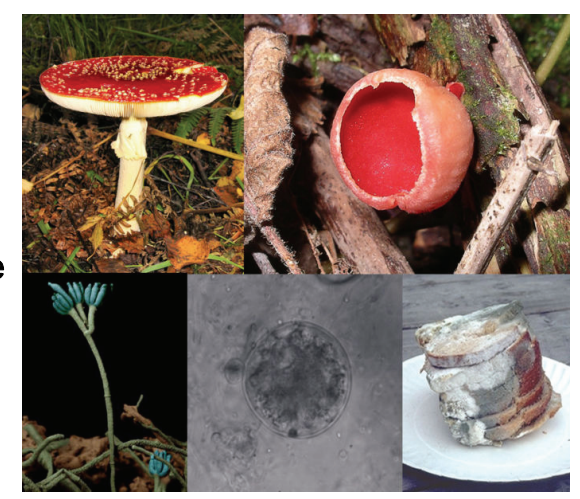
small and look like a fine powder when see with bare eyes. Can anyone name of another type of fungus? Bread mold, mold in blue cheese, mildew, toadstools, yeast, etc.

One common fungus that can cause health problems is mold. Has anyone seen mold before? Where did you see it? Household locations such as bathrooms. Mold is a fungus that produces spores in order to reproduce. The spores continually move through the air and land on surfaces that can promote growth.

One place l've seen mold is in the bathroom around my shower. What do you think the mold likes about my shower? Warmth, moisture, food. Molds like warm places and moisture, and, like all living organisms, they need food to stay alive. Today, we are going to create our own environments for mold to grow in. 
Prior to selecting the food, ask students to predict which food types might grow mold the fastest and slowest. Predict which jars will grow the largest and smallest amounts of mold. Have students write their predictions on the back of their record sheet. This provides a discussion reference at the end of the activity.

STEP 1: Give students an opportunity to choose food for their jar. Encourage students to think about what molds need in order to grow and which foods might grow the best mold garden.

STEP 2: Students should dip each piece of food into a bowl of water and then place them in the jar (try to keep all of the food close enough to touch but not piled into a heap).

STEP 3: Put the lid on the jar. Use tape to write each child's name on his/her jar and to tape around the lid to make sure it is secure.
STEP 4: Place jars in a place where they can remain undisturbed for a few days (WARMTH enhances growth, so near a window would be favorable). For the first couple of days, you will not see much, if any, mold, but within the next few days you should begin to see fuzzy white and green mold growing on the food.

STEP 5: If possible, allow students to periodically take pictures of their terrariums during the mold growing. If photographs are not possible, have students to draw the progression of the mold. the progression either in photographs or in drawings will be added to their newspaper.

STEP 6: To dispose of jars: Carefully place sealed jars into a trash bag. Tie the trash bag and place into a garbage dumpster.

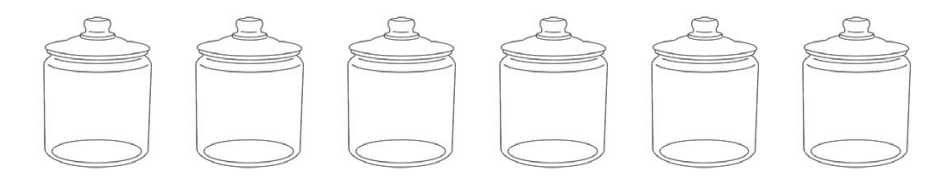

\section{RXTRA! WXTRA! 'THINK ALL ABOUT' IT!}

\section{LET'g REFLECT}

1. Which food grew mold the fastest? The slowest? What do you think caused some foods to grow mold better than the others?

2. How did your predictions about which foods would grow mold the quickest compare to the results? How about your predictions about the amount of mold?

3. What steps did you use to collect and record information about your garden? How did you display the results to create a story about your garden?

4. Were there different molds growing in the jar? How do you know? Where do you think these molds came from?

5. It would be dangerous for us to open our containers once mold begins to grow. Why do you think this is?

\section{FAST FACTS Some molds have beneficial uses to us. did youknow? \\ Penicillin, the most commonly used antibiotic, is derived from mold.}

Some cheeses, like blue cheese are supposed to be moldy. Blue cheese gets its flavor and name from the veins of the blue-green mold in it.

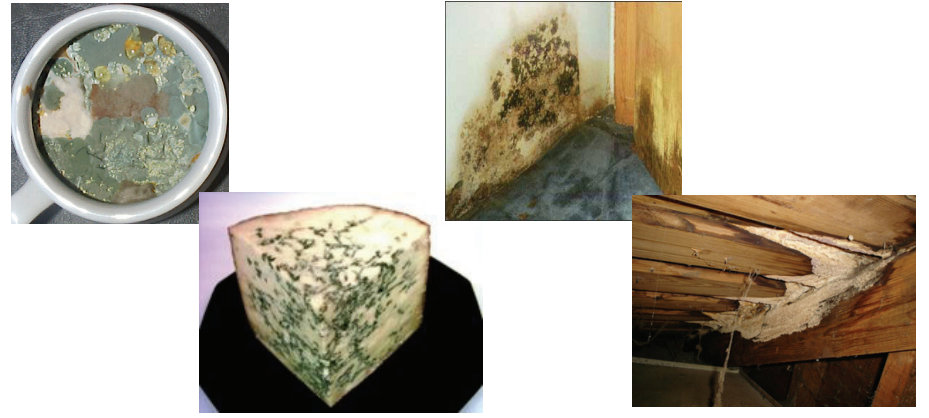

\section{LET'g APPLY}

1. How could you share the information you collected about your mold garden with others? Which type of data do you think would be the most convincing? Why?

2. Why is important to develop a regular schedule of collecting data when performing an experiment over time?

3. What challenges are there with recording and interpreting data?

4. What other professionals might use similar experiments to study growth? (Doctors monitoring culturing growth, scientists studying plant food or pesticides, etc.) 
This assignment is part of a series of newspaper-related pieces that each student will include in his/her own Children's Environmental Health Newspaper. At the conclusion of this unit, students will bring the newspapers home to educate parents and other family members about the possible dangers in their own environments.

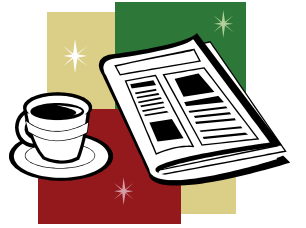

Have students create a graphic. This graphic will be placed with their next piece (which is a

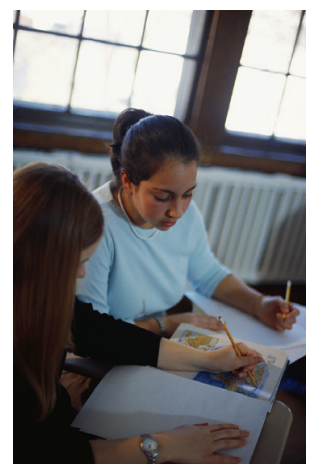

Healthy Homes Column). It will need to have a caption that accompanies it.

- They may choose to re-draw any of their observations from the Gross-Out Garden.

OR

- They may create a small graphic strip showing the changes that the foods underwent over time.

To aid students in creating the above newspaper pieces, refer them back to the Editor's TIP SHEET on “Using Graphics and Advertising."

Need more ideas? Below are activities that can be integrated into this lesson for a challenge or to provide variety.

- Before the experiment have students draw a picture of how they predict the mold growth will look.

- Have students to examine pre-made slides of different types of molds and fungi with a microscope.

\section{N口TES:}

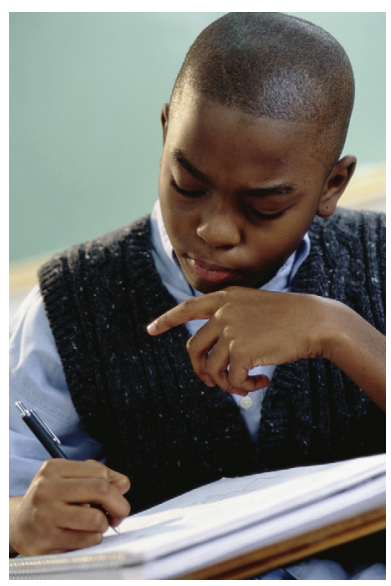


What's Growing On?

Keep track of what you see in your jar every day...

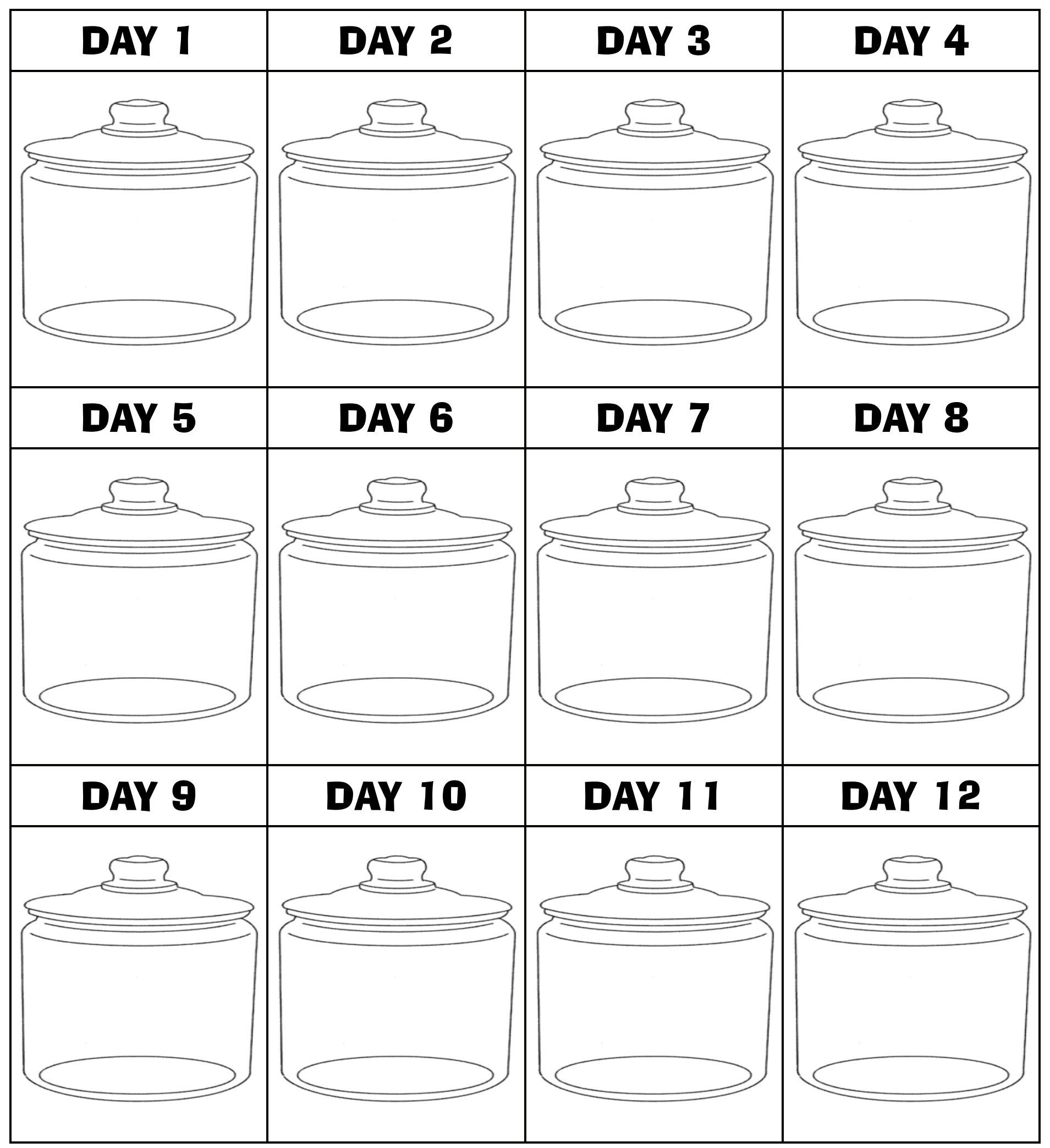


